\title{
CORPO E EDUCAÇÃO NO ESCOTISMO A PARTIR DA REVISTA O TICO TICO (1921-1933)
}

BODY AND EDUCATION IN SCOUTING BASED ON O TICO TICO MAGAZINE (1921-1933)

\author{
CUERPO Y EDUCACIÓN EN EL MOVIMIENTO SCOUT DESDE LA \\ REVISTA O TICO O TICO (1921-1933)
}

\section{Carlos Herold Junior}

Palavras-chave Movimento escoteiro. Educação corporal. Revistas. História.

\section{Keywords:}

Boys Scouts.

Body education.

Magazines. History.

Palabras clave Movimiento Scout. Educación corporal. Revistas. Historia.
Resumo: $O$ objetivo deste trabalho é analisar a importância da educação corporal no interior do escotismo nas primeiras décadas do século XX. Foram analisados textos publicados na revista O Tico Tico publicados entre 1921 e 1931. Verificou-se que o escotismo foi divulgado no Brasil como uma prática educacional coadunada às modernidades pedagógicas pela consideração a respeito das atividades do corpo.
Abstract: The purpose of this study is to analyze the importance of body education in Scouting in the early decades of the twentieth century. It analyzed texts published in O Tico Tico magazine between 1921 and 1931. Scouting was found to be publicized in Brazil as an educational practice linked to pedagogical modernities because of its consideration of body activities.

Resumen: El objetivo de este trabajo es analizar la importancia de la educación corporal en el Movimiento Scout en las primeras décadas del siglo XX. Textos publicados en la Revista O Tico Tico, publicados entre 1921 y 1931 fueron analizados. Se encontró que el Movimiento Scout fue divulgado en Brasil como una práctica educativa junto a modernidades pedagógicas mediante la consideración de las actividades corporales.
*Universidade Estadual de Maringá. Maringá, PR, Brasil.

E-mail: carlosherold@ hotmail.com

Recebido em: 15-07-2014

Aprovado em: 03-11-2014

(c) (i) () Licence 


\section{CONSIDERAÇÕES INICIAIS}

O objetivo deste trabalho é analisar a importância da educação corporal no interior do escotismo nas primeiras décadas do século XX. A colocação desse objetivo sustenta-se no apoio oferecido por outros trabalhos que também focalizam desdobramentos históricos do movimento escoteiro. Macleod (1983), Macdonald (1993) e Jeal (2001) abordam o movimento em sua expansão pela Europa e Estados Unidos. Souza (2000), Zuquim e Cytrynowicz (2002), Gabriel (2003), Nascimento (2004), Thomé (2006) e Nascimento (2008) pensam dimensões educacionais da história do escotismo a partir da sua chegada ao Brasil em 1910. Em Ferreira Neto e Neitzel (2006), Oliveira (2007)' , Putcha (2007) e Linhales (2009a) a educação corporal no seio das ideias e práticas escoteiras é mencionada de forma secundária no interior das análises de cada um desses trabalhos. 0 corpo e a educação escoteira são temas centrais nos estudos de Scharadgrodsky (2008), Watt (2009) e Herold Junior e Vaz (2012). Ao perseguirmos o objetivo acima pretendemos colaborar com esse conjunto bibliográfico sublinhando 0 escotismo do início do século XX como um fenômeno de grande valor temático e analítico para a história da educação corporal no Brasil.

Documentalmente, as reflexões serão construídas a partir de textos publicados em uma coluna ${ }^{2}$ que divulgava o escotismo na revista O Tico Tico $(\mathrm{RTT})^{3}$. A coluna circulou, regularmente, entre 1921 e 1933, tendo como principal redator Benjamin Sodré (1892-1982)4.

Para análise desse material empírico, lançaremos mão do que Chartier (2002) chama de representação. As representações surgem "à revelia dos actores sociais" de forma que elas "descrevem a sociedade tal como pensam que ela é, ou como gostaria que fosse" (CHARTIER, 2002, p. 19). Será focalizada a tensão entre "práticas e representações" à medida que na RTT a educação corporal no escotismo se "dá a ler" (p. 17), exibindo-se como "presença, como apresentação pública de algo" (p.20); mas, igualmente, como um esforço "dando a ver uma coisa ausente" (p. 20). Estudaremos a importância das atividades do corpo na formação moral e cívica da infância e da juventude, bem como o valor do escotismo na realização dessas "verdades", em sua relação com "os pontos de afrontamento" (CHARTIER, 2002, p. 17). Na $\mathrm{RTT}$ esses afrontamentos se evidenciam como práticas corporais incorretas ou como ausência de práticas vistas como naturais, formativas e/ou endossadas pela ciência, algo avaliado como gerador de problemas sociais e culturais no Brasil das primeiras décadas do século XX. Demonstraremos que a importância do escotismo se dava à medida que propunha educar por meio de atividades corporais que deveriam contornar dois problemas: 1) os "excessos", observados em determinadas práticas corporais que, por isso, iam de encontro aos preceitos oriundos da renovação pedagógica; 2) e a desconsideração em relação ao corpo na educação, observada nas estruturas educacionais formais, igualmente avaliadas como contrárias aos avanços da aplicação científica à pedagogia. Para a discussão desses dois pontos, os trabalhos

1 OLIVEIRA, M. A. Taborda de. Educando pelo corpo: saberes e práticas na instrução pública primária paranaense (finais do séc. XIX, início do séc. XX). In: CONGRESSO BRASILEIRO DE CIÊNCIAS DO ESPORTE, 15., CONGRESSO INTERNACIONAL DE CIÊNCIAS DO ESPORTE, 2., 2007, Recife. Anais... 2007.

2 A coluna teve início com o título Escotismo. A partir de 25 de março de 1925 ela passou a ser publicada com o título de Escoteirismo. Depois do número publicado em 19 de fevereiro de 1930 ela volta ao antigo nome, Escotismo. Houve uma grande quantidade de textos sobre o escotismo publicados na revista e que não apareceram na coluna em foco. Mesmo que a ênfase seja dada à referida coluna, serão utilizados alguns textos publicados antes de 1921 que tocam diretamente 0 escopo deste artigo.

3 Os números consultados para a realização deste estudo estão disponíveis na Hemeroteca Digital da Biblioteca Nacional: <http:// hemerotecadigital.bn.br/artigos/o-tico-tico>. A consulta foi feita em abril de 2013, com as seguintes palavras-chave: escotismo e escoteirismo. 
de Gonçalves (2013), Oliveira (2013) e Linhales (2009b) também serão usados como suportes teóricos ao diálogo com fontes.

Dividimos as reflexões em três momentos: inicialmente, focalizamos aspectos concernentes à fundação e à expansão do escotismo. Ainda na primeira parte evidenciamos a importância da RTT na divulgação de variadas plataformas educacionais circulantes no Brasil no período. Na parte 2, investigamos representações circulantes na RTT que constatavam uma crise moral e educacional, sustentada na expansão da vida urbana e no afastamento dos meninos em relação à natureza. Por fim, apresentamos e avaliamos representações sobre a possibilidade de solução desse problema: o escotismo e sua ênfase na educação corporal, "dados a ler" (CHARTIER, 2002, p. 17) na RTT como fatos necessários e endossados pela ciência.

\section{ESCOTISMO E A IMPORTÂNCIA DA RTT NO BRASIL}

\subsection{A expansão do escotismo}

O escotismo foi criado na Inglaterra em 1907. Robert Baden-Powell (1857-1941) justificava sua proposta pelo fato de ela fazer frente a uma tendência de seu tempo, por ele avaliada como deletéria: a diminuição dos esforços físicos e morais necessários para 0 enfrentamento dos problemas da vida (BADEN-POWELL, 1922, p. 10). O conforto proporcionado pela técnica seria a causa de um declínio da constituição humana (sobretudo, dos homens) 5 . Macleod (1983, p. 33) constata que, do século XIX ao XX, os Estados Unidos e a Europa lidaram com o que foi chamado de boy problem, ou seja, a constatação da fraqueza moral e física dos meninos, resultantes da expansão da vida urbana. A urgência de se buscar meios para frear essa tendência colocou em relevo a educação dos futuros cidadãos como a única condição para contornar uma decadência vista como iminente. Palluau (2013, p. 17) mostra que o escotismo foi tomado como o ponto de partida para a "solução pedagógica da questão social".

O sucesso do escotismo nas primeiras décadas do século XX se sustentou no fato de ele ter lidado com limites educacionais existentes tanto nas estruturas educacionais formais quanto na educação familiar e cotidiana das crianças e dos jovens. Ao advogar sua proposição formativa, o escotismo se espalhou pelo mundo, angariando simpatizantes e praticantes em países de todos os continentes. Na Inglaterra, Macdonald (1993, p.10) mostra que, de 1909 a 1917, o número de escoteiros saltou de 9.000 para 194.000. Jeal (2001, p. IX) calcula que, entre a criação do movimento e o ano de 2001, passaram pelo escotismo 550.000 .000 de membros.

A rápida expansão do movimento escoteiro aconteceu também na América do Sul. Considerando dados da World Organization of the Scout Movement, o escotismo atingiu muitos países sul-americanos apenas alguns anos após sua criação: Chile - 1909; Brasil 1910; Peru - 1911; Argentina - 1912; Venezuela e Colômbia - 1913; Bolívia - 1915, Equador - 1920 (SCOUTS, 2012).

A inserção das ideias escoteiras no panorama socioeducacional do período foi possibilitada e estimulada, também, pela grande quantidade de livros, artigos e periódicos publicados sobre 
escotismo. Jeal (2001, p. 376) evidencia que, desde o surgimento do movimento, Robert BadenPowell contou com assessoria profissional para tornar tudo que escrevia mais divulgado e mais aceito. Nascimento (2008) endossa essa constatação e complementa dizendo que a expansão do escotismo teve como um de seus estimuladores o uso de imensa quantidade de periódicos voltados à divulgação de práticas e ideias escoteiras. Essa estratégia fez com que não apenas as instâncias centrais do movimento publicassem e divulgassem seus impressos, mas, igualmente, muitos grupos espalhados pelo mundo afora fizessem circular folhetos ou pequenos jornais. Eles propagandeavam suas atividades, pondo em destaque as consequências delas à moralidade, à saúde, à responsabilidade e à coragem da infância e da juventude.

\subsection{A revista 0 Tico Tico (RTT) e a educação da infância e juventude brasileiras}

No Brasil, de forma bem mais ampla ao que era possível aos restritos jornais escoteiros que circulavam no país, a RTT exerceu esse e outros papéis. A amplitude de sua circulação e a intensidade com que privilegiou aspirações sociopolíticas na sociedade brasileira do início do século XX a tornaram uma das mais importantes propagadoras de muitas bandeiras educacionais. Vergueiro (2005) afirma que a RTT é um "marco na indústria editorial brasileira", sendo que os 56 anos 6 em que ela circulou regularmente fizeram-na a publicação infantil de maior influência nacional. Vergueiro (2008) observa que a preocupação educacional caracterizava a publicação. Ele explica que a RTT "Mesclava elementos de civismo e preceitos religiosos do catolicismo" (VERGUEIRO, 2008, p. 29).

Ao lado da importância educacional ${ }^{7}$ da RTT, Hansen (2004) lembra que ela foi um empreendimento comercial ${ }^{8}$. É um traço revelador do início do século XX o mercado editorial brasileiro voltado à infância ter lançado mão de uma expressiva feição formativa para realizar pretensões econômicas. Isso diz muito sobre a recepção e a ânsia da sociedade ao olhar para as crianças, preocupando-se com sua formação cívica, moral e corporal. Gonçalves (2013, p. 118) enxerga na RTT uma "desejo propriamente intelectual de investimento político na educação infantil".

Merlo (2004, p. 10) ${ }^{9}$ sublinha o fato de a RTT ter servido como grande divulgadora do escotismo. Esse apoio é visto como justificado pela semelhança entre os valores defendidos pelos editores e pelos dirigentes do movimento. Vergueiro (2005) explica a semelhança entre a linha editorial da RTT e as bases ideológicas e pedagógicas do escotismo, tendo como pilares "[...] a disciplina, a honra, o cumprimento dos deveres e a prática de exercícios físicos para 0 desenvolvimento moral e intelectual dos indivíduos" (VERGUEIRO, 2005, p. 182). Vem dessa semelhança a participação de Benjamin Sodré na redação da RTT. Sobre o início da atuação do pai na RTT e a importância da revista para a sociedade e para o escotismo, afirma Dora Sodré na biografia de Benjamin Sodré, por ela escrita:

6 A RTT teve seu primeiro número publicado em 1905.

7 Deve ser observado que essa importância educacional também não era unanimemente aceita. Gonçalo Junior (2004, p.132) mostra que no interior da Associação Brasileira de Educação (ABE), havia grande resistência à RTT, justificada pela ingenuidade das histórias e o fato de a revista ensinar hábitos considerados estrangeiros.

8 Coelho observa que a relação entre entretenimento e educação era característica de boa parte da literatura dirigida às crianças: "Instruir ou divertir? Eis o problema que está longe de ser resolvido. As opiniões divergem e em certas épocas se radicalizam. Entretanto, se analisarmos as grandes obras que através dos tempos se impuseram como "literatura infantil", veremos que pertencem simultaneamente a essas duas áreas distintas (embora limítrofes e, as mais das vezes, interdependentes): a da Arte e da Pedagogia" (COELHO, 1991, p.42). 
Foi nesse ano, 1921, que Papai começou a escrever para O Tico Tico uma secção de Escotismo, e que teve grande repercussão e apoio de pessoas de alto nível, entre elas Coelho Neto, Ruy Barbosa, Olavo Bilac, que muito se interessaram também pelo movimento. (SODRÉ, 1989, p.42)

No interior dessa divulgação da importância formativa do escotismo, a educação corporal ganhou evidência nos anos de 1920.

\section{ESCOTISMO, A VIDA MODERNA E A REAPROXIMAÇÃO À NATUREZA ${ }^{10}$ PELO FORTA- LECIMENTO DO CORPO}

Oliveira (2013, p. 87 ) nota que o começo do século assistiu a uma "preocupação difusa com os rumos da educação" que tocou as sociedades de maneira geral. No Brasil, especificamente, Linhales (2009b, p. 332) observa que as discussões concernentes à "falta de energia dos brasileiros" davam conta da existência de uma "problemática nacional". Em que pese às especificidades de cada contexto, essa situação levou à defesa de um "retorno à natureza" (OLIVEIRA, 2013, p. 93) ou uma busca de uma "reconciliação do homem com a natureza" (OLIVEIRA, 2013, p. 93). Macleod (1983), analisando o já mencionado boy problem ao abordar a sociedade norte-americana do período, mostra que essa ânsia por uma reaproximação à natureza levou políticos e educadores a representarem as crianças do meio rural como moralmente mais sólidas e corporalmente mais saudáveis. Elas se constituíram, assim, em um modelo para os meninos das grandes cidades. Gonçalves (2013) pondera que na RTT, todavia, a dita vocação agrícola brasileira era criticada, mesmo que muitas narrativas fossem "[...] ambientadas no interior, mostrando onde estavam guardadas as verdadeiras riquezas do Brasil" (GONÇALVES, 2013, p. 131).

Por outro lado, Oliveira (2013, p. 94) nos lembra que o "mito de uma educação 'natural"' não dizia respeito, apenas, à natureza externa com a qual dever-se-ia retomar o íntimo contato perdido com o tempo: tratava-se de buscar a "condição natural do homem e da cultura". Nessa busca pela natureza humana, o corpo ganhou grande destaque no pensamento daqueles que buscavam entender as angústias educacionais que vivenciavam.

No Brasil, a efervescência das grandes cidades no início do século XX (SEVCENKO, 1992) também provocou inquietações sociais e educacionais que possibilitaram grande receptividade ao escotismo. Meninos marcados pela debilidade e pela falta de patriotismo encontravam-se nessa situação pois, "se divertem nos cinemas, respirando 0 ar viciado próprio daquellas casas de diversão, [...] ou a fingirem de homens de mentira, sentados nas mesas dos cafés, de cigarrinho no canto da bocca [...]" (ESCOTISMO, 1922a, p. 37-38). As críticas feitas às comodidades da vida urbana que se expandia no Brasil se sustentavam no resultado que esses confortos gerariam nos rapazes: falta de vigor e de patriotismo. Percebemos nessas advertências o que Oliveira (2013, p.93) chama de "ênfases sobre uma educação para a dureza".

A aversão à rudeza da vida, caracterizadora de uma modernidade pintada com cores fortemente críticas, tinha, porém, seus admiradores no Brasil: os "almofadinhas". De acordo

\footnotetext{
10 Ultrapassa aos objetivos deste artigo uma análise histórica sobre as transformações conceituais consoantes à natureza e aos pares natureza-cultura e natureza-educação. Partimos do reconhecimento de que, de um lado, a "ideia de um caráter benéfico da natureza para a saúde do homem" (VILLARET, 2005, p.19) é uma longa tradição na história ocidental. De outro, o "desejo de conformar a educação à natureza é, sem dúvida, uma aparição tardia” (ULMANN, 1987, p.13), remontando ao século XVIII. A demonstração dos modos como, no início do século XX, o escotismo lidou com essa problemática é uma agenda de pesquisa muito promissora, que se fortalece se considerarmos as representações circulantes na RTT.
} 
com a RTT eles eram inimigos do país a serem combatidos por rapazes fortes e responsáveis. Travou-se uma batalha contra hábitos e comportamentos fomentadores de desânimo e que disseminavam do "homem feminil" (A VIDA..., 1930, p. 29): temia-se a perda da virilidade e da energia, o que faria os homens semelhantes às mulheres. Macleod (1983, p. 46) evidencia o medo sentido por educadores ao notarem que, em muitos casos, as mulheres estariam se tornando "mais viris que os homens". Proctor (2009) explicita que esse medo transformavase em absoluto pavor quando abordado pelos defensores do escotismo. Por isso, no Brasil, o escotismo colocava-se como solução, desde que se seguisse o seguinte preceito: "Não prendei os vossos filhos. Deixae-os respirar o ar livre e saudável dos campos, educandose, aprendendo, guiados por instructores solícitos, nos quais podemos ter toda a confiança" (ESCOTISMO, 1922a, p. 15-16). O escotismo recomporia uma vida aproximada à natureza e às exigências que ela colocava ao corpo, à moral e à inteligência do homem: "No fim de pouco tempo o escoteiro é um homem, forte, viril, e energico. Na vida calma e de excessivo conforto da cidade, sem nunca della sahir, é que não se podem educar com energia" (ESCOTISMO, 1924b, p. 15, grifo nosso). Importante considerar que nas histórias publicadas na RTT "as meninas raramente apareciam como foco principal" (GONÇALVES, 2013, p. 118).

Essa volta à natureza fazia do escotismo uma medida patriótica que possibilitaria ao Brasil ser "arrancado do descrédito em que caminha" (ASSOCIAÇÃO..., 1923, p. 16). Por essa razão lemos na RTT, publicado em caixa alta, o seguinte apelo: "SÊDE OS PRIMEIROS A ENVIAR OS VOSSOS FILHOS, BRASILEIROS DE AMANHÃ, PARA AS FILEIRAS ENGRANDECEDORAS DO 'ESCOTISMO'”(O ESCOTISMO..., 1922d, p. 8). 0 atendimento a esse pedido levaria a uma mocidade capaz de "erguer o nome deste Brasil immenso". Nessa grande obra, o escotismo representava um "papel de grande valor na creação physica e moral do rapaz" (O ESCOTISMO..., 1922d, p. 8). Gonçalves (2013, p. 114) confirma que na RTT "a idealização do Brasil como um país do futuro é uma mitologia recorrente".

Mesmo com a recorrência dessa mitologia e sendo a luta para realizá-la o grande alvo do escotismo, o movimento expandia-se com dificuldades: "É o progresso do modernismo, que faz o jovem tornar-se almofadinha, e trocar o ar severo do homem másculo, pelos requebros e elegâncias do homem feminil!" (O ESCOTISMO..., 1923d, p. 17). Ao fazer essas advertências sobre a perda de espaço do "homem másculo", é observado que os esforços que naquele presente eram dirigidos para a aparência antigamente eram voltados para se "conseguir um physico bom e uma moral optima". Essa ambição educacional era, porém, secundarizada pelo "fazer-se mimoso e delicado, dansar bem, manejar o baralho e ser sympathisado pelas moças (O ESCOTISMO..., 1923d, p. 17). O escotismo seria fundamental para a reversão da decadência dos ditos almofadinhas: "Que isso não vos desanime ó jovens que praticaes o Escotismo (O ESCOTISMO..., 1923d, p. 17). A condição para realizar essa promessa era "todos rapazes brasileiros de hoje, de 11 a 18 annos, se inscreverem como escoteiros num Grupo ou patrulha". Abraçar o escotismo era um "dever de todos os meninos brasileiros que amam de verdade a sua patria" (ESCOTISMO, 1923a, p. 17).

\section{ESCOTISMO COMO EDUCAÇÃO MODERNA}

A representação da natureza como algo a ser reconquistado ocorreu nos marcos do movimento de "renovação pedagógica" no início do século XX (OLIVEIRA, 2013). 
Essa constatação é importante para as reflexões deste artigo, pois ela vai ao encontro de outro constante esforço dos defensores do escotismo: divulgá-lo como proposta que teria revolucionado a pedagogia. Essa característica pedagógica do escotismo seria justificada pela ciência. Taborda de Oliveira (2013, p. 93) diz que "a ciência e cientificismo contribuíram para repor a natureza no centro dos processos educativos". Isso, do mesmo modo, fez com que muitos estudiosos da educação voltassem sua atenção ao movimento criado por Baden-Powell.

Em Genebra, Jean Piaget (1896-1980) e Pierre Bovet (1878-1965) publicaram textos endossando a importância pedagógica da proposta escoteira. Piaget, ao estudar a educação moral, em 1930, afirma: "quando Baden-Powell busca relatar, em seus escritos, os artigos de sua pedagogia moral, não suplanta em quase nada os melhores autores sobre as lições de moral. Mas, na prática, que psicologia!" (PIAGET, 1996, p. 26). Bovet é ainda mais eloquente na sua admiração pelos sucessos pedagógicos do escotismo. Ao apresentar o livro que redigira sobre esses sucessos, O gênio de Baden-Powell, Bovet escreve:

\footnotetext{
Baden-Powell é para mim um educador de primeira grandeza, porque uma intuição genial Ihe deu, num momento, um conhecimento sem igual da alma do rapaz.... tentarei legitimar minha admiração por Baden-Powell, mostrando a surpreendente concordância do programa escotista com o que hoje conhecemos da psicologia do rapaz (BOVET, 1939, p. 7, grifo nosso).
}

No Brasil a mesma postura de atribuir méritos científicos e pedagógicos ao movimento escoteiro existiu em análises e artigos voltados aos professores. Em 1935, Gabriel Skinner, chefe escoteiro e defensor da Educação Física, publicou um artigo na Revista de Educação Física do Exército, no qual afirmou: "O escotismo, pode-se dizer, é a consubstanciação da ciência pedagógica moderna" (SKINNER, 1935, p.40). Helena Antipoff, também em 1935 e na mesma revista, afirma: "Não nos esqueçamos de que a escola de Baden-Powell representa uma obra de educação integral do adolescente [...]" (ANTIPOFF, 1935, p.1).

$\mathrm{Na}$ RTT, da mesma maneira, a obra de Baden-Powell é vista como realizadora de muitos preceitos pedagógicos que já eram assumidos como corretos, mas ainda não praticados nas realidades escolares. Por isso, colocava-se o escotismo ao lado da "obra de Cristo" (ESCOTISMO, 1931a, p. 23) pela sua importância aliada a sua simplicidade. Essas características seriam os principais distintivos do legado de Baden-Powell.

Além deles, outro mérito da modernidade educacional do escotismo, de acordo com a RTT, era ensinar por meio de brincadeiras. Essa capacidade de educar de modo prazeroso faria frente a uma realidade educacional centrada no intelecto:

\footnotetext{
A educação ministrada aos nossos filhos nos collegios, com raras excepções, age quase exclusivamente sobre a mentalidade das creanças e abandona a educação physica [...]. Pois bem, o escotismo se propõe, e consegue, completar essa falha na educação das creanças (ESCOTISMO, 1921, p. 14).
}

Gonçalves (2013) nota que na RTT havia uma crítica à "escola real", que funcionava à base de "castigos físicos regulares e exercícios de repetição intermináveis" (p.136). No escotismo a dinâmica pedagógica seria diferente: "Uma aula de civismo, dada insípida e monotonamente na Escola, duas semanas depois já se desvaneceu do espirito da maioria. Dada a brincar no escotismo, firma-se para sempre" (ESCOTISMO, 1925a, p. 14).

Macleod (1983) sublinha que desdobramentos nos estudos da psicologia impactaram, positivamente, a pujança pedagógica do escotismo. No início do século XX as análises de 
Stanley Hall (1844-1924) sobre a adolescência popularizaram a ideia de que a melhor maneira de se abordar essa "passagem da selvageria à civilização" (MACLEOD,1983 , p. 99) que seria a adolescência devesse ocorrer através de uma grande atenção à natureza corporal do jovem: "Os construtores de caráter insistiram, consequentemente, que os garotos devem controlar seus instintos por meio de uma recreação ativa e supervisionada" (MACLEOD, 1983, p. 99). A partir das reflexões de Hall a adolescência passou a ser vista como o momento da vida mais "[...] sensível a todos os melhores e mais sábios empenhos dos adultos" (HALL apud SAVAGE, 2009, p. 88).

Esse apoio buscado na ciência fortalecia as críticas do escotismo às estruturas educacionais formais. A educação escoteira conseguia aproximar-se da "alma do rapaz" (BOVET, 1939, p.7) por "atacar simultaneamente vários pontos", justamente por não "ser muito methodisada". Trabalhando a cada dia de forma paulatina, no escotismo a educação era prática e marcada pelos "movimentos da gymnastica sueca" e pelas "evoluções de marcha" (ESCOTISMO, 1922b, p. 15). Ou seja, tratava-se de posicionar o escotismo ao lado do que havia de mais moderno em termos educacionais, criticando a escola por limitar-se à instrução. Instruir era visto como insuficiente. Desse modo, concluía-se que "A escola instrue. O escotismo educa" (ESCOTISMO, 1924a, p. 17). Educava pois ele estaria atento ao corpo.

\subsection{A modernidade pedagógica das atividades corporais praticadas no escotismo}

Nesse prisma de aproximação da educação às modernidades pedagógicas endossadas pela ciência, a correção das propostas escoteiras era defendida pela ênfase que elas davam aos "exercicios ao ar livre, de longas caminhadas, de sports conhecidos e jogos especiaes". Através deles, "o menino Escoteiro adquire uma saude e um vigor extraordinários" (AS LIÇÕES..., 1917, p. 5). Oliveira (2013, p. 105) apoia essa consideração, ajudando-nos a inferir que a ênfase escoteira nessas atividades, para além do "conhecimento utilitário e pragmático da natureza", levava ao "desenvolvimento de um senso estético, atributo básico de homens e mulheres de cultura e espírito elevados e de uma sociedade que se pudesse chamar civilizada".

Para promover essa ênfase, buscou-se a medida correta para a intensidade da movimentação corporal. As atividades do corpo deveriam ter como característica a moderação, algo visto como ausente no que já era considerado um hábito na década de 1920: jogar futebol. Linhales (2009b, p. 341) diz que a "popularização do esporte e sua extensão às massas puseram em relevo as preocupações com a mocidade e a infância". Desse ponto de vista, o "cigarrinho no canto da bocca" era tão prejudicial para os meninos como eram as horas que passavam a se "esfaltarem num campo de football". Isso geraria "infallivelmente lesões no coração". Não era essa a postura dos escoteiros: eles deveriam ir "para o campo, respirar 0 ar saudável que lhes dará mais saude e vida, ondem tambem joguem o football, mas com moderação [...]" (ESCOTISMO, 1922a, p. 37-38). Linhales (2009b) faz a seguinte ponderação: "Note-se que esses novos praticantes do esporte - as camadas populares e os jovens da população - foram frequentemente representados em um sentido essencialmente negativo, vinculado à ideia de massa desordenada, desagregada e desprovida de disciplina" (LINHALES, 2009b, p. 341). Era o fortalecimento corporal que faria o Brasil ter mais importância política no mundo. Todavia, esse fortalecimento era visto como ainda não alcançado, devido à incorreção imputada ao modo como o esporte era praticado: "Praticar todos os 'sports', fugindo 
ás especialisações sempre prejudiciaes" era atitude necessária para realizar a "continua preoccupação de fortalecer o corpo e o caracter e purificar a alma [...]" (ESCOTISMO, 1922c, p. 18). Mesmo algumas atividades tipicamente escoteiras eram criticadas por serem praticadas equivocadamente, a partir desse prisma. Um exemplo disso vemos em um número da RTT que fez as seguintes considerações sobre a marcha: "Evitar sempre as grandes marchas, extenuantes, e sobretudo os raids inúteis cujo fim unico seja vencer distancias. Nada há de mais condemnavel no escotismo" (ESCOTISMO, 1925b, p. 14). Dito de outro modo, ser uma "atividade escoteira" não garantiria a superação da tão criticada falta de ratio.

Para que a ênfase educacional ao corpo tocasse dimensões morais e intelectuais, as atividades deveriam acontecer como se propunha no escotismo: "tudo feito com método e prudência [...]" (ESCOTISMO, 1931b, p. 14). Era pelo corpo e suas atividades racionalmente regradas que o escotismo angariava simpatizantes. Afinal, a valorização das atividades corporais escoteiras se baseava na ideia de que as ambições formativas não se reduziam ao aspecto corporal: o escotismo não seria "só um methodo de cultura physica. [...], possue como "escopo" um grado muito elevado, o aperfeiçoamento da moral e da intelligencia" (LIÇÕES..., 1923 e, p. 5). Uma semana depois, voltou-se à questão, sendo ela explicada de forma mais detalhada: ainda que o escotismo não devesse ser, apenas, "como muita gente erradamente pensa, um methodo de cultura physica", não poderia ser negligenciado que "Um corpo que não esteja robustecido, trenado, agil, não póde, de fórma alguma, guardar um espirito dado ao bem e ao cumprimento do dever" (LIÇÕES..., 1923f, p. 5). Então, cultivar fisicamente as crianças e os jovens deveria ser uma preocupação relacionada ao incremento moral e intelectual. Por isso os jogos escoteiros eram "exercicios naturaes, praticados com inteliggencia, moderação e prudência" (ESCOTIMO, 1924a, p. 17).

No difícil balanço entre razão e emoção, entre esforço e prazer, o jogo foi abraçado como proposta que colocaria os meninos em contato com a natureza externa e a sua própria natureza infantil e/ou juvenil, formando-os "robustos, vigorosos, sadios" (ESCOTISMO, 1931a, p. 14). O jogo era concebido como o principal artefato pedagógico para realizar essa ampla educação que tinha no corpo o seu ponto de partida e a sua condição de realização. Quando se afirmava serem as atividades escoteiras um jogo, sublinhava-se que elas redundariam na formação de "cavalheiros ao serviço de Deus, da Patria e do próximo" e que o método escoteiro auxiliaria a educação que acontecia na Igreja, no lar e na escola. Essa ajuda teria como resultado "dar vida aos rapazes e completar a sua formação moral, intelectual e physica" (ESCOTISMO, 1923b, p. 17). Metodologicamente, esse amplo leque formativo seria realizado da seguinte forma:

\footnotetext{
Os jogos violentos, de desenvolvimento physico, serão alternados com os calmos, de obervação e estudo, de sorte a não fatigar os meninos. Difficilmente se consegue corrigir o espirito de uma creança por meio de palavras. Pelos jogos no entanto consegue-se, porque os jogos escoteiros são a educação e a moral em acção (ESCOTISMO, 1923c, p. 14).
}

Embora essas representações fossem divulgadas como irrefutáveis, notamos a dificuldade desse pretenso valor pedagógico fazer eco na realidade. A resistência dos educadores à importância dessas ideias era presente, e o incômodo sobre ela se manifestou na RTT: "lastimável, que ainda não houvéssemos chamado a nós tão excellente auxiliar" (ESCOTISMO, 1921, p. 14). Mesmo que a educação, de forma geral, ainda relutasse em assumir as atividades corporais como meios formativos, em uma das colunas lê-se o elogio a uma escola por ela ter adotado o escotismo, recheando seu dia a dia com muitas de suas 
atividades: "Gymnasticas, banhos de sol, natação, vida ao ar livre, á sombra perfumosa de magnífico pomar" (A VIDA..., 1930, p. 19). Sublinhar um exemplo isolado evidencia o tamanho do esforço em se descrever a educação do momento como os divulgadores do escotismo "gostariam que fosse" (CHARTIER, 2002, p. 19).

\section{CONSIDERAÇÕES FINAIS}

O alcance que tiveram o escotismo e a RTT no início do século $X X$ foi considerado fenômeno de grande importância neste trabalho para pensarmos a história da educação corporal daquele momento. Como um movimento extraescolar, o escotismo participou, através das ideias e práticas que divulgava, da "preocupação difusa" (OLIVEIRA, 2013, p. 87) que fomentou 0 processo de "criação e disseminação de organismos e entidades internacionais voltadas para o fomento da renovação educacional" (OLIVEIRA, 2013, p. 89). A RTT, por sua vez, "foi um dos símbolos do processo de modernização da imprensa brasileira" (GONÇALVES, 2013, p. 115).

A proposição escoteira foi representada como revolucionária em termos pedagógicos. Ela remediaria tanto a desatenção ao corpo de uma escola que valorizava apenas o intelecto quanto a prática não moderada (lê-se não científica) de atividades corporais. Ela faria frente a posturas sinalizadoras de um cotidiano marcado por vícios e comportamentos a serem educacionalmente extirpados.

Sustentando essa constatação, esteve a busca por uma educação que deixasse de formar jovens preguiçosos. Ela assolava o Brasil, colocando-o em uma posição inferior. Para efetivar essa reversão, o escotismo foi avaliado, ao mesmo tempo, como uma obra divina e como uma realização cabal da aplicação científica à pedagogia. Entretanto, nem o fervor religioso, nem a precisão científica impediram observações amargas sobre o fato de essas certezas não serem suficientes para barrar a adoção de atitudes vistas como não másculas por parte da infância e da juventude: depreendemos da leitura dos artigos da RTT a frequência do "exagero" nos esportes e o imobilismo das escolas. Essas posturas redundavam em uma "massa desordenada" (LINHALES, 2009b, p. 341) e nos igualmente antipatrióticos "almofadinhas" e "homens feminis". Perfis frequentemente associados às grandes cidades, eles deveriam deixar de existir. Pelo seu esforço desmedido ou pela sua fraqueza corpórea, eles materializavam a crise moral que estaria levando aquela sociedade à falta de apego aos valores tradicionais, assumidos como os mais aproximados à natureza.

Concluindo, as reflexões demonstraram que, na conjugação do movimento escoteiro e da RTT, as atividades corporais e a educação moral e cívica obtida através delas marcaram representações caracterizadoras de uma grande esperança na educação da infância e da juventude brasileiras durante a década de 1920.

\section{REFERÊNCIAS}

ANTIPOFF, Helena. A escola e o escotismo. Revista de Educação Física do Exército, Rio de Janeiro, n. 25, p. 2-3, 1935. Disponível em: <http://revistadeeducacaofisica.com.br/ artigos/1935/25_aescolaescotismo.pdf>. Acesso em: 12 jun. 2011. 
ASSOCIAÇÃO de escoteiros catholicos do Brasil. O Tico Tico, Rio de Janeiro, v. 18, n. 902, p. 15-16, 17 jan. 1923.

BADEN-POWELL, Robert. Rovering to success: a book of life-sport for young men. London: J. Jenkis, 1922.

BADEN-POWELL, Robert. Scouting and youth movements. London: Ernest Benn, 1929.

BOVET, Pierre. O Gênio de Baden-Powell: o que é preciso compreender do escotismo. Rio de Janeiro: União dos Escoteiros do Brasil, 1939.

CHARTIER, Roger. A história cultural: entre práticas e representações. Rio de Janeiro: Bertrand Brasil, 2002.

COELHO, Nelly Novaes. Literatura infantil: teoria, análise, didática. 5. ed. rev. São Paulo: Ática, 1991.

ESCOTISMO. 0 Tico Tico, Rio de Janeiro, v. 16, n. 847, p. 14, 28 dez. 1921.

ESCOTISMO. O Tico Tico, Rio de Janeiro, v. 17, n. 850, p. 15, 11 jan. 1922a.

ESCOTISMO. O Tico Tico, Rio de Janeiro, v. 17, n. 853, p. 14-15, 8 fev. 1922b.

ESCOTISMO. 0 Tico Tico, Rio de Janeiro, v. 17, n. 864, p. 17-18, 26 abr. 1922c.

ESCOTISMO. O Tico Tico, Rio de Janeiro, v. 18, n. 925, p. 16-18, 27 jun. 1923a.

ESCOTISMO. O Tico Tico, Rio de Janeiro, v. 18, n. 928, p. 17-18, 18 jul. $1923 b$.

ESCOTISMO. 0 Tico Tico, Rio de Janeiro, v. 18, n. 943, p. 13-15, p. 15-16, 31 out. 1923c.

ESCOTISMO. 0 Tico Tico, Rio de Janeiro, v. 19, n. 964, p. 17-18, 26 mar. 1924a.

ESCOTISMO. 0 Tico Tico, Rio de Janeiro, v. 19, n. 978, p. p. 15, 2 jul. 1924b.

ESCOTISMO. O Tico Tico, Rio de Janeiro, v. 20, n. 1005, p. 14-15, 7 jan. 1925a.

ESCOTISMO. 0 Tico Tico, Rio de Janeiro, v. 20, n. 1007, p. 14-15, 21 jan. 1925b.

ESCOTISMO. 0 Tico Tico, Rio de Janeiro, v. 28, n. 1348, p. 23, 5 ago. 1931a.

ESCOTISMO. 0 Tico Tico, Rio de Janeiro, v. 28, n. 1359, p. 14-15, 21 out. 1931 b.

ESCOTISMO. O Tico-Tico, Rio de Janeiro, v. 12, n. 626, p. 5, 3 out. 1917.

O ESCOTISMO e a grandeza da nação. 0 Tico Tico, Rio de Janeiro, v. 17, n. 888, p. 17-18, 11 out. 1922d.

O ESCOTISMO no Pará. 0 Tico Tico, Rio de Janeiro, v. 18, n. 916, 25 abr. 1923d.

FERREIRA NETO, Amarílio; NEITZEL, Fernanda. "Didatics", games, scouts, physical, psychological and moral formation of a child. The FIEP bulletin, Foz do Iguaçu, v. 76, n. 1, p. 284-287, 2006. Disponível em: <http://www.proteoria.org/>. Acesso em: 21 ago. 2009.

GABRIEL, Y. C. Prescrições cívico-morais e a formação do cidadão: um estudo sobre a introdução do escotismo nas escolas públicas de São Paulo (1917-1922). Dissertação (Mestrado 
em Educação) - Pontifícia Universidade Católica de São Paulo, São Paulo, 2003.

GONÇALO JUNIOR. A guerra dos gibis: a formação do mercado edital brasileiro e a censura aos quadrinhos, 1933-1964. São Paulo: Companhia das Letras, 2004.

GONÇALVES, Roberta Ferreira. A escola em brincadeiras: intelectuais e nação na criação da revista O Tico-Tico. In: CARULA, K. et al. (Org.). Os intelectuais e a nação: educação, saúde e a construção de Brasil moderno. Rio de Janeiro: Contra Capa, 2013.

HANSEN, Patrícia Santos. Brasil, um país novo: literatura cívico-pedagógica e a construção de um ideal de infância brasileira na Primeira República. 253 f.. Tese (Doutorado em História) Faculdade de Filosofia, Letras e Ciências Humanas, Universidade de São Paulo, São Paulo, 2004.

HEROLD JUNIOR, Carlos; VAZ, Alexandre Fernandez. A educação corporal em Baden-Powell: o movimento escoteiro contra o intelectualismo escolar. Revista HISTEDBR On-line, v. 47, p. 166-184, 2012. Disponível em: <http://www.fae.unicamp.br/revista/index.php/histedbr/article/ view/4212/3418>. Acesso em: 10 jul. 2014.

JEAL, Tim. Baden-Powell: founder of the boy scouts. New Heaven: Yale University Press, 2001. LIÇÕES de vovô. O Tico Tico, Rio de Janeiro, v. 18, n. 923, p. 15-16, 13 jun. 1923 e.

LIÇÕES de vovô. 0 Tico Tico, Rio de Janeiro, v. 18, n. 924, p. 15-16, 20 jun. $1923 f$.

LINHALES, Meily Assbú. A escola e o esporte: uma história de práticas culturais. São Paulo: Cortez, 2009a.

LINHALES, Meily Assbú. Esporte e escola: astúcias da "energização do caráter" dos brasileiros. In: DEL PRIORE, M.; MELO, V. A. de. (Org.). História do esporte no Brasil: do império aos dias atuais. São Paulo: Editora da Unesp, 2009b. p. 331-358.

MACDONALD, Robert H. Sons of the Empire: the Frontier and the Boy Scout Movement, 18901918. Toronto: University of Toronto, 1993.

MACLEOD, David. Building Character in the American boy: the boy scouts, YMCA, and their forerunners, 1870-1920. London: The University of Wisconsin Press, 1983.

NASCIMENTO, Amailson de Oliveira. Educação e civismo: movimento escoteiro em Minas Gerais (1926-1930). Revista Brasileira de História da Educação, Maringá, n. 7, p. 43-74, 2004.

NASCIMENTO, Jorge Carvalho do. A escola de Baden-Powell: cultura escoteira, associação voluntária e escotismo de estado no Brasil. Rio de Janeiro: Imago, 2008.

NASCIMENTO, Jorge Carvalho do. O escotismo e os impressos IV. In: EDUCAÇÃO e História. Disponível em: < http://jorge.carvalho.zip.net/arch2008-03-30_2008-04-05.html >. Acesso em: 30 out. 2011.

OLIVEIRA, Marcus Aurélio Taborda de. Em busca da natureza negada: a renovação pedagógica e o mito de uma educação "natural". In: OLIVEIRA, Marcus Aurélio. T. de (Org.). Sentidos e sensibilidades: sua educação na história. Curitiba: Editora UFPR, 2013. p. 87-108.

PALLUAU, Nicholas. La fabrique des pédagogues: encadrer les colonies de vacances (19191939). Rennes: Presses Universitaires de Rennes, 2013. 
de educação moral. São Paulo: Casa do Psicólogo, 1996. p. 1-36.

PROCTOR, Tammy. Scouting for girls: a century of girl guides and girl scouts. Santa Barbara, California: ABC Clio, 2009.

PUCHTA, Diogo Rodrigues. A formação do homem forte: educação física e gymnastica no ensino público primário paranaense (1882-1924). 126 f. Dissertação (Mestrado) - Curso de Pósgraduação em Educação da UFPR, 2007.

SAVAGE, Jon. A criação da juventude. Rio de Janeiro: Rocco, 2009.

SCHARADGRODSKY, Pablo Ariel. El scautismo em la educación física bonaerense: Argentina o acerca del buen encauzamiento varonil (1914-1916). Revista Brasileira de Ciências do Esporte, Florianópolis, v. 29, n. 3, p. 155-177, 2008.

SCOUTS. Some statistics. Disponível em: <http://scout.org/en/around_the_world/countries/ national_scout_organisations/some_statistics>. Acesso em: 3 jun. 2012.

SEVECENKO, Nicolau. Orfeu extático na metrópole. São Paulo: Companhia das Letras, 1992.

SKINNER, Gabriel. Características primaciais do Escotismo. Revista de Educação Física, Rio de Janeiro, n. 23, p. 39-30, 1935. Disponível em: <http://revistadeeducacaofisica.com.br/ artigos/1935/23_caracteristicas.pdf>. Acesso em: 9 jul. 2011.

SODRÉ, Dora. A educação pelo exemplo: momentos da vida de Benjamin Sodré. Rio de Janeiro: Erca, 1989.

SOUZA, Rosa Fátima de. A militarização da infância: expressões do nacionalismo na cultura brasileira. Cadernos CEDES, Campinas, v. 22, n. 52, p.104-121, 2000.

THOMÉ, Nilson. Movimento escoteiro: projeto educativo extra-escolar. Revista HISTEDBROnline, Campinas, n. 23, p. 171-194, 2006. Disponível em <http://www.escoteiros.org.br/ arquivos/trabalhos_academicos/movimento_escoteiro_projeto_educativo_extra_escolar.pdf>. Acesso em: 10 jul. 2014.

ULMANN, Jacques. La nature et l'éducation: I'ideé de nature dans la education physique et dans l'éducation morale. Paris: Éditions Klincksieck, 1987.

VERGUEIRO, Waldomiro de Castro Santos. A postura educativa de O Tico-Tico: uma análise da primeira revista brasileira de história em quadrinhos. Comunicação \& Educação, São Paulo, n. 2, p.23-34, 2008.

VERGUEIRO, Waldomiro de Castro Santos. O Tico-Tico e a expansão do escotismo no Brasil. In: VERGUEIRO, W; SATNTOS, R. E. dos. (Org.). O Tico-Tico: 100 anos da primeira revista de quadrinhos brasileira. São Paulo: Opera Graphica, 2005. v. 1, p. 181-184.

A VIDA ao ar livre. O Tico Tico, Rio de Janeiro, v. 26, n. 1273, p. 30, 26 fev. 1930.

VILLARET, Sylvan. Naturisme et éducation corporelle: des projets réformistes aux prises em compte politiques et éducatives (XIXe - milieu du XXe siècles). Paris: L'Harmattan, 2005.

WATT, Carey. No showy muscles: the boy scouts and the global dimension of physical culture and bodily health in Britain and colonial India. In: BLOCK, N.; PROCTOR, T. M. (Org.). Scouting frontiers: youth and the scout movement's first century. Cambridge: Cambridge Scholars, 2009. p. 121-142. 
ZUQUIM, Judith; CYTRYNOWICZ, Roney. Notas para uma história do escotismo no Brasil: a "psicologia escoteira" e a teoria do caráter como pedagogia de civismo. (1914-1937). Educação em Revista, Belo Horizonte, n. 35, p. 43-58, 2002. 